\title{
Thioredoxin2 enhances the damaged DNA binding activity of mtTFA through direct interaction
}

\author{
AKIHIKO KIDANI ${ }^{1,2}$, HIROTO IZUMI ${ }^{1}$, YOICHIRO YOSHIDA ${ }^{3}$, EIJI KASHIWAGI ${ }^{1}$, HARUKI OHMORI ${ }^{2}$, \\ TSUNEO TANAKA ${ }^{2}$, MICHIHIKO KUWANO ${ }^{4}$ and KIMITOSHI KOHNO ${ }^{1}$ \\ ${ }^{1}$ Department of Molecular Biology, School of Medicine, University of Occupational and Environmental Health, \\ Kitakyushu; ${ }^{2}$ Department of Digestive and General Surgery, Faculty of Medicine, Shimane University, \\ Izumo; ${ }^{3}$ Osaka Rosai Hospital, Surgery, Sakai; ${ }^{4}$ Innovative Anticancer Diagnosis and Therapeutics, \\ Innovation Center for Medical Redox Navigation, Kyushu University, Fukuoka, Japan
}

Received July 22, 2009; Accepted September 16, 2009

DOI: 10.3892/ijo_00000462

\begin{abstract}
Mitochondrial transcription factor A (mtTFA) is a member of the HMG (high mobility group)-box protein family. We previously showed that mtTFA preferentially binds to both cisplatin-damaged and oxidatively damaged DNA. In this study, we found that expression levels of both mtTFA and the mitochondrial antioxidant protein thioredoxin2 (TRX2) are upregulated in cisplatin-resistant cell lines. In addition, TRX2 directly interacts with mtTFA and enhances its damaged DNA binding activity. The interaction between mtTFA and TRX2 requires the HMG box 1 motif of mtTFA. Furthermore, when amino acid substitutions were introduced at either C49G or C246stop, TRX2 interacted with mtTFA. However, the interaction of TRX2 with mtTFA was enhanced when both mutations (C49G and C246stop) were introduced. Binding to cisplatin-damaged DNA was similar among mutant mtTFA proteins. By contrast, binding to oxidized DNA was significantly enhanced when double mutations were introduced. These results suggest that TRX2 not only functions as an antioxidant, but also supports mtTFA functions.
\end{abstract}

\section{Introduction}

The cytotoxic action of cisplatin is believed to result from the formation of covalent adducts with DNA. We have previously

Correspondence to: Dr Kimitoshi Kohno, Department of Molecular Biology, School of Medicine, University of Occupational and Environmental Health, 1-1 Iseigaoka, Yahatanishi-ku, Kitakyushu 807-8555, Japan

E-mail: k-kohno@med.uoeh-u.ac.jp

Abbreviations: HMG, high mobility group; mtDNA, mitochondrial DNA; PCR, polymerase chain reaction; GST, glutathione S-transferase; EDTA, ethylenediaminetetraacetic acid; DTT, dithiothreitol; PMSF, phenylmethylsulfonyl fluoride; SDS, sodium dodecyl sulfate; PBS, phosphate-buffered saline

Key words: mitochondrial transcription factor A, thioredoxin2, DNA damage reported that cisplatin-targeted sequences, such as G-stretch sequences, are more numerous in humans and gorillas than in rodents, frogs and flies (1). Furthermore, G-stretch sequences appear much more frequently in mtDNA than in nuclear DNA. Thus, we propose that mtDNA might be the main target of cisplatin.

Reactive oxygen species (ROS) have been implicated in various pathologies (2-11). mtDNA is more susceptible to oxidative damage than genomic DNA because of its lack of a nucleosome structure. mtTFA is a member of the HMG-box protein family (12), members of which stimulate transcription by binding to the D-loop region of mtDNA and function in mtDNA maintenance and repair $(13,14)$. Nuclear HMG-box proteins bind preferentially to cisplatin-damaged DNA (15-18). We have previously shown that mtTFA also preferentially recognizes oxidatively damaged DNA as well as cisplatindamaged DNA (19). The enhanced binding affinity of mtTFA for damaged DNA may suggest that mtTFA protects mtDNA from various DNA damage. Additionally, mtTFA plays an important role in apoptosis. In the present study, we found that the expression levels of both mtTFA and TRX2 are upregulated in cisplatin-resistant cells. We also investigated the physical and functional interaction between mtTFA and TRX2. We found that TRX2 directly interacts with mtTFA. Our findings suggest that TRX2 not only functions as an antioxidant defense, but also cooperatively acts to support mtTFA functions.

\section{Materials and methods}

Cell culture. Human epithelial cancer HeLa cells were cultured in Eagle's minimal essential medium containing $8 \%$ fetal bovine serum, which was purchased from Nissui Seiyaku (Tokyo, Japan). Cisplatin-resistant HeLa/CP4 cells were derived from HeLa cells as described previously (20) and were found to be 23 to 63 -fold more resistant to cisplatin than their parental cells (21). Cell lines were maintained in a $5 \% \mathrm{CO}_{2}$ atmosphere at $37^{\circ} \mathrm{C}$.

Antibodies. Anti-mtTFA was prepared as previously described (22). Anti-TRX2 (HPA000994) antibody, anti-Flag (M2) 
antibody, anti-Flag (M2) affinity gel and anti- $\beta$-actin (AC-15) antibody were purchased from Sigma (St Louis, MO, USA). Anti-HA-peroxidase (3F10) was purchased from Roche Molecular Biochemicals (Mannheim, Germany).

Plasmid construction. To obtain the full-length complementary DNA (cDNA) for human TRX2, PCR was carried out on a SuperScript cDNA library (Invitrogen, San Diego, CA) using the following primer pair: 5'-GGATCCATGGCTCAGCG ACTTCTTCTGAG-3' and 5'-TCAGCCAATCAGCTTCTT CAGGAAGG-3'. Underlines indicate the start and stop codons. The PCR product was cloned into the pGEM-T easy vector (Promega, Madison, WI). To construct Flag-tagged TRX2 expression plasmid in bacteria, the EcoRI fragment of TRX2 cDNA was ligated into the TH-Flag vector (23). For construction of pcDNA3-Flag-TRX2, N-terminal Flagtagged TRX2 cDNAs were ligated into a pcDNA3 vector (Invitrogen, San Diego, CA). The construction of GST-mtTFA, GST-mtTFA $\Delta 1.2$, GST-mtTFA $\Delta 2$, and GST-mtTFA $\Delta 1$ has been described previously (19). GST-mtTFA-CC (wild-type), -GC (cysteine 49 to glycine), -CX (cysteine 246 to stop codon), and -GX (cysteine 49 to glycine and cysteine 246 to stop codon) were obtained by PCR using the following primer pairs: CC, 5'-TGGCAAGTTGTCCAAAGAAACC-3' and 5'-TTTTAACACTCCTCAGCACC-3'; GC, 5'-TGGCA AGTGGTCCAAAGAAACC-3' and 5'-TTTTAACACTCCT CAGCACC-3'; CX, 5'-TGGCAAGTTGTCCAAAGAAAC-3' and 5'-TTTTATCACTCCTCAGCACC-3'; GX, 5'-TGGCA AGTGGTCCAAAGAAACC-3' and 5'-TTTTATCACTCC TCAGCACC-3'.

Expression and purification of GST-fusion proteins. Expression and purification of GST-fusion proteins were performed as described previously (19). Briefly, GST fusion proteins induced by $1 \mathrm{mM}$ isopropyl- $\beta$-D-thiogalactopyranoside (Boehringer Mannheim, Mannheim, Germany) were sonicated in binding buffer $(50 \mathrm{mM}$ Tris- $\mathrm{HCl} \mathrm{pH} 8.0$, $1 \mathrm{mM}$ EDTA, $120 \mathrm{mM} \mathrm{NaCl}, 10 \%$ glycerol, $0.5 \%$ Nonidet P-40, $1 \mathrm{mM}$ DTT, and $0.5 \mathrm{mM}$ PMSF), and soluble fractions were mixed with glutathione-Sepharose 4B (GE Healthcare Bio-Science). GST-fusion proteins eluted with $50 \mathrm{mM}$ Tris$\mathrm{HCl}(\mathrm{pH} 8.0)$ and $20 \mathrm{mM}$ reduced glutathione according to the manufacturer's protocol (Pharmacia, Uppsala, Sweden) were separated in SDS $10 \%$ polyacrylamide slab gels. Gel strips containing the fractionated proteins were cut and homogenized in elution-renaturation buffer (1\% Triton X-100, $20 \mathrm{mM}$ HEPES pH 7.6, 1 mM EDTA, $100 \mathrm{mM} \mathrm{NaCl,} 2 \mathrm{mM}$ DTT, $0.1 \mathrm{mM}$ PMSF). The eluted proteins were dialyzed in dialysis buffer (50 mM Tris- $\mathrm{HCl} \mathrm{pH} 7.5)$ using a PlusOne Mini Dialysis kit (Amersham Biosciences, Piscataway, NJ).

Co-immunoprecipitation assay. Transient transfection and immunoprecipitation assays were performed as described previously $(23,24)$. Briefly, $2 \times 10^{5} \mathrm{HeLa}$ cells were seeded into $35-\mathrm{mm}$ tissue culture plates. The following day, cells were transfected with $1 \mu \mathrm{g}$ of each of HA- and Flag-fused expression plasmids using SuperFect reagent (Qiagen, Hilden, Germany) according to the manufacturer's instructions. At $6 \mathrm{~h}$ post-transfection, the cells were washed with $\mathrm{PBS}$, cultured at $37^{\circ} \mathrm{C}$ for $48 \mathrm{~h}$ in fresh medium and then lysed in buffer $\mathrm{X}$ containing $50 \mathrm{mM}$ Tris- $\mathrm{HCl}$ (pH 8.0), 1 mM EDTA, $120 \mathrm{mM}$

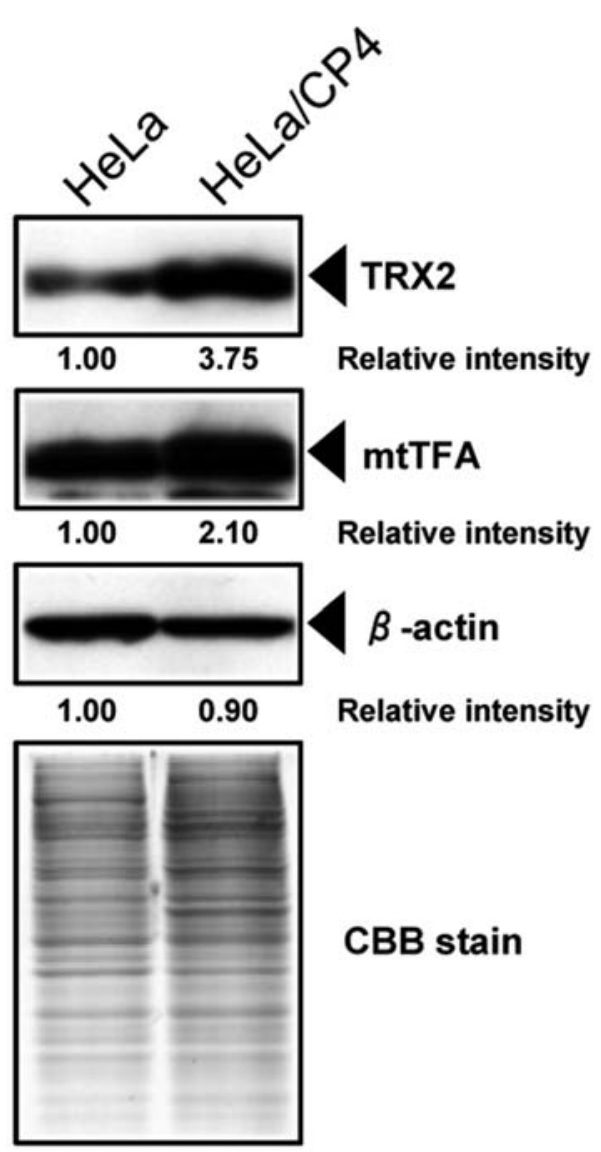

Figure 1. mtTFA and TRX2 are up-regulated in cisplatin-resistant cells. Whole-cell extracts (50 $\mu \mathrm{g}$ for mtTFA and $20 \mu \mathrm{g}$ for TRX2) were subjected to SDS-PAGE, and Western blot analysis was done with antibodies against mtTFA, TRX2 and B-actin (loading control). Relative intensity is shown under each blot. Gel staining with Coomassie brilliant blue (CBB) is also shown.

$\mathrm{NaCl}, 0.5 \%$ (v/v) Nonidet P-40 (NP-40), $10 \%$ (v/v) glycerol, $1 \mathrm{mM}$ PMSF, and $1 \mathrm{mM}$ DTT. The lysates were centrifuged at $21,000 \mathrm{x} \mathrm{g}$ for $10 \mathrm{~min}$ at $4^{\circ} \mathrm{C}$ and supernatants $(300 \mu \mathrm{g})$ were incubated for $2 \mathrm{~h}$ at $4^{\circ} \mathrm{C}$ with anti-Flag (M2) affinity gel. Immunoprecipitated samples were washed three times with buffer $\mathrm{X}$ and subjected to subsequent Western blot analysis.

GST pull-down assay. Expression of TH-Flag-TRX2 and serial deletion mutants of GST-mtTFA in bacteria and GST pull-down assays were carried out as described previously (25). GST-mtTFA or its deletion mutants immobilized on glutathione-sepharose $4 \mathrm{~B}$ were incubated with soluble bacterial extracts containing Flag-TRX2 for $2 \mathrm{~h}$ at $4^{\circ} \mathrm{C}$ in buffer X. Bound samples were washed three times with buffer $\mathrm{X}$ and subjected to Western blot analysis with anti-Flag antibody.

Western blot analysis. Whole-cell lysates and nuclear extracts were prepared as described previously $(23,26)$. The indicated amounts of whole-cell lysates and nuclear extracts or immunoprecipitated samples were separated by SDS-polyacrylamide gel electrophoresis (PAGE) and transferred to polyvinylidene difluoride microporous membranes (Millipore, Bedford, MA, USA) using a semidry blotter. Blotted membranes were treated with $3 \%$ (w/v) skimmed milk in $10 \mathrm{mM}$ Tris, $150 \mathrm{mM} \mathrm{NaCl}$ 
A
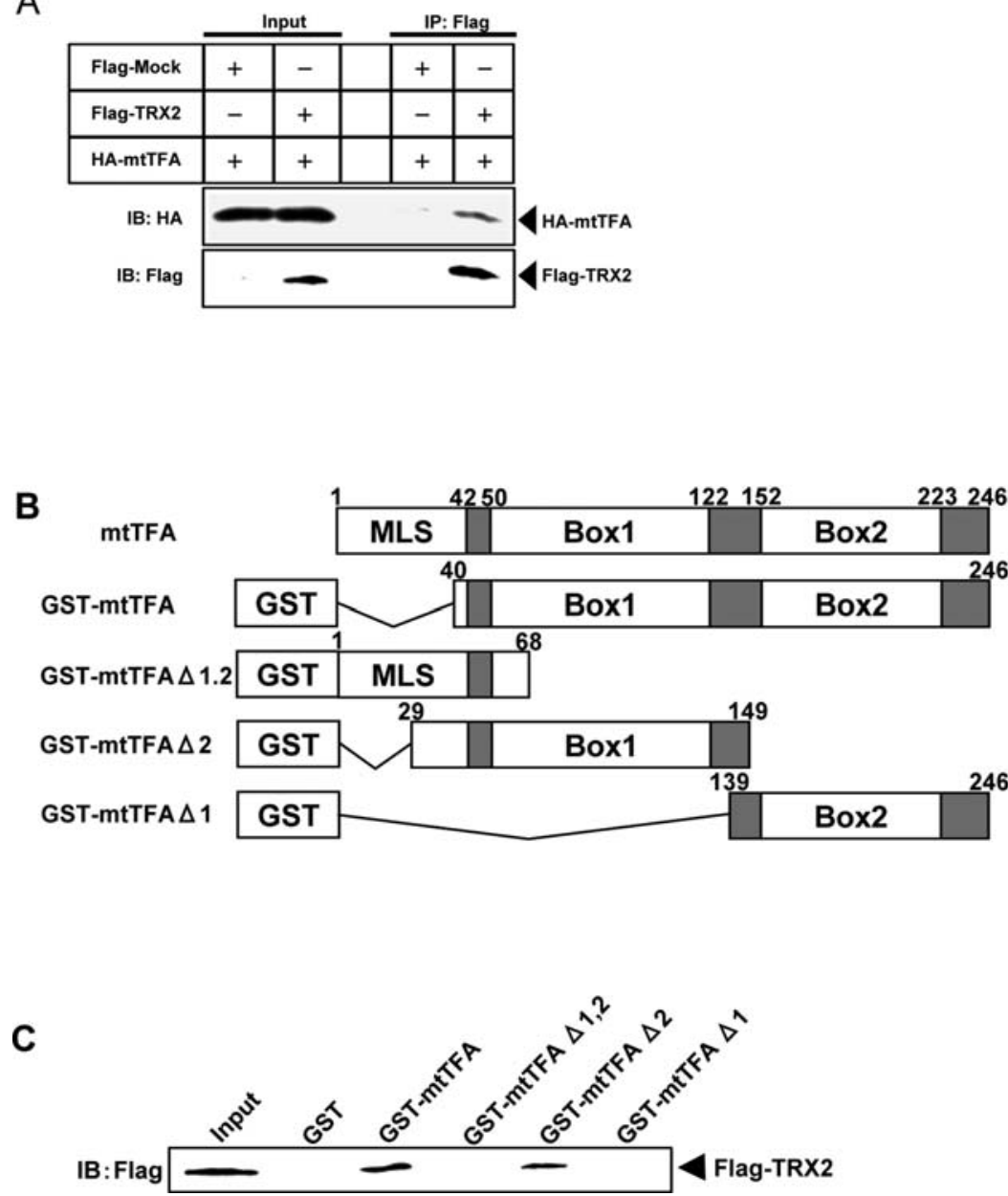

Figure 2. TRX2 directly interacts with the HMG-box 1 motif of mtTFA. (A) Whole-cell extracts (300 $\mu \mathrm{g})$ prepared from HeLa cells co-transfected with indicated expression plasmids were immunoprecipitated with anti-Flag (M2) antibody. The resulting immunocomplexes and whole-cell extracts (30 $\mu \mathrm{g}$ ) were subjected to SDS-PAGE, and Western blot analysis was performed using anti-HA and anti-Flag (M2) antibodies. (B) Schematic representation of GSTmtTFA fusion protein and the deletion mutants used in this assay. The two HMG-boxes are indicated as Box 1 and Box 2. MLS indicates mitochondrial localizing sequences. (C) GST fusion proteins immobilized on glutathione-sepharose 4B beads were incubated with Flag-TRX2 expressed in bacteria. Bound protein samples representing $10 \%$ of the input were subjected to SDS-PAGE and Western blot analysis with an anti-Flag antibody.

and $0.2 \%(\mathrm{v} / \mathrm{v})$ Tween-20, and incubated for $2 \mathrm{~h}$ at room temperature with primary antibody. The following antibodies and dilutions were used: a 1:1000 dilution of anti-mtTFA (22), a 1:1000 dilution of anti-TRX2, a 1:10,000 dilution of anti- - -actin, and a 1:7500 dilution of anti-Flag (M2). Membranes were then incubated for $45 \mathrm{~min}$ at room temperature with a peroxidase-conjugated secondary antibody or a 1:5000 dilution of anti-HA-peroxidase. Bound antibody was visualized using an enhanced chemiluminescence kit (GE Healthcare Biosciences, Piscataway, NJ, USA) and membranes were exposed to Kodak X-OMAT film (Kodak, Paris, France). For the correlation assay the intensity of each signal was quantified using the NIH imaging program, version $1.63(\mathrm{NIH}$, Bethesda, MD, USA).

Electrophoretic mobility shift assay (EMSA). Preparation of oligonucleotides and EMSAs were performed as described previously (19). Briefly, the following annealed 22-mer duplexes were prepared: 5'-GGTGGCCTGACXCATTCCC CAA-3' and 3'-ACCGGACTGYGTAAGGGGTTGG-5', where $\mathrm{X}=\mathrm{G}$ or 8 -oxo-dG and $\mathrm{Y}=\mathrm{A}, \mathrm{C}, \mathrm{G}$ or $\mathrm{T}$. Duplexes (22-mers) were end-labeled with $\left[\alpha^{-32} \mathrm{P}\right] \mathrm{dCTP}$ using the Klenow fragment for extension, and gel-purified. Half the volume of the labeled oligonucleotide without 8-oxo-dG was treated with $0.3 \mathrm{mM}$ cisplatin at $37^{\circ} \mathrm{C}$ for $12 \mathrm{~h}$, and then purified by ethanol precipitation. Purified GST fusion proteins were used directly in EMSAs. Reaction mixtures contained $5 \%$ glycerol, $10 \mathrm{mM}$ Tris- $\mathrm{HCl} \mathrm{pH} 7.5,50 \mathrm{mM} \mathrm{NaCl}, 0.1 \mathrm{mM}$ EDTA, $1 \mathrm{mM}$ DTT, $0.4 \mathrm{ng} / \mu \mathrm{l}$ of ${ }^{32} \mathrm{P}$-labeled probe DNA and the indicated amounts of GST fusion proteins, and were mixed. Binding reactions were incubated for $5 \mathrm{~min}$ at room temperature. Products were analyzed on $4 \%$ polyacrylamide gels in $0.5 \mathrm{X}$ Tris-borate EDTA buffer using a bioimaging analyzer (BAS 2000; Fuji Photo Film, Tokyo) (19).

\section{Results}

Both mtTFA and TRX2 are expressed in cisplatin-resistant cells. We previously showed that p53 interacts with mtTFA and enhances the DNA binding activity of mtTFA to cisplatindamaged DNA, but inhibits its binding to oxidatively damaged DNA (22). Cisplatin induces both DNA damage and oxidative 
A

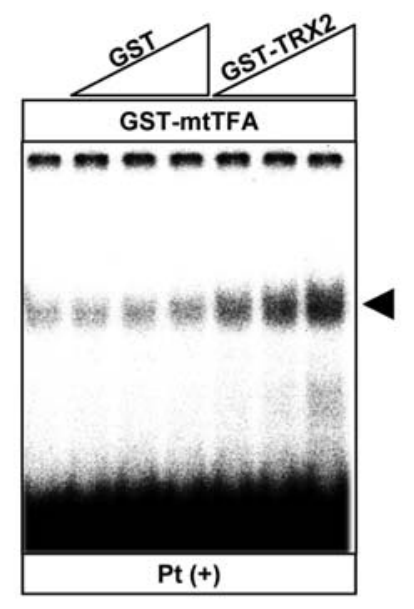

B

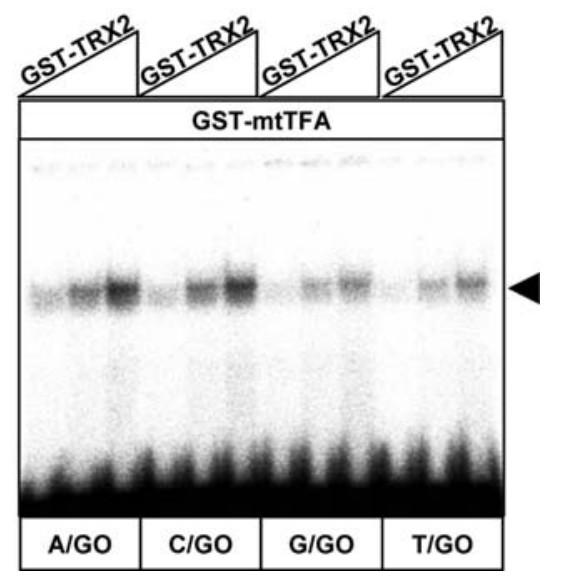

Figure 3. Effect of TRX2 on the binding of cisplatin-damaged or oxidatively damaged DNA by mtTFA. (A) Purified GST-mtTFA (90 ng) were mixed with GST or GST-TRX2 $(10,30$ and $90 \mathrm{ng})$ and incubated with ${ }^{32} \mathrm{P}$-labeled double-stranded oligonucleotides $(0.4 \mathrm{ng} / \mu \mathrm{l})$ containing cisplatin cross-linked. Binding complexes were subjected to EMSA. The arrowhead indicates DNA-protein complexes. (B) Effect of TRX2 on mtTFA binding to mismatchcontaining oxidized oligonucleotides. Increasing amounts of GST-TRX2 $(10,30$ and $90 \mathrm{ng})$ were mixed with GST-mtTFA (90 ng) and incubated with the indicated ${ }^{32} \mathrm{P}$-labeled double-stranded oligonucleotides containing mismatches (A/GO, C/GO, G/GO and T/GO). Binding complexes were subjected to EMSAs. GO indicates 8-oxo-dG. The arrowhead indicates DNAprotein complexes.

stress in mitochondria and thioredoxin 1 is upregulated in cisplatin resistant cells. Based on these previous results, we first examined the expression of mtTFA and the antioxidant protein TRX2 in cisplatin-resistant cells. The expression levels of both mtTFA and TRX2 were upregulated in cisplatinresistant cells (Fig. 1).

Interaction of TRX2 with mtTFA. We then next investigated whether TRX2 interacts with mtTFA. As shown in Fig. 2A, mtTFA interacts with TRX2 in vivo. To confirm the association and binding site, we performed a pull-down assay using immobilized GST-fusion proteins comprising mtTFA deletion mutants and Flag-TRX2 (Fig. 2B). This assay demonstrated that the HMG box 1 motif of mtTFA directly participates in the interaction, but that the HMG box 2 motif does not (Fig. 2C).
Effect of TRX2 association on the binding of mtTFA to damaged DNA. We previously showed that the HMG box 1 motif possesses damaged DNA binding activity, but that the HMG box 2 motif does not (19). The interaction of mtTFA with TRX2 may alter the damaged DNA binding activity of mtTFA. An EMSA showed that GST-mtTFA can form a specific complex with cisplatin-damaged DNA and mismatchcontaining DNA with 8-oxo dG. We observed that addition of TRX2 to the mtTFA-DNA binding reaction resulted in significant enhancement of binding of mtTFA to both cisplatindamaged DNA and oxidatively damaged DNA (Fig. 3A and B).

mtTFA structure regulates the association with TRX2. It has been shown that mtTFA formed multimers under physiological conditions (27). To confirm whether the interaction of TRX2 with mtTFA requires a specific structure of mtTFA, we introduced mutations at two cysteine residues, positions 49 and 246, as shown in Fig. 4A. Pull-down assays showed that two mtTFA mutants, mtTFA-GC and mtTFA-CX, interacted with TRX2 with the same affinity as wild-type mtTFA-CC. However, the association of mtTFA with TRX2 was significantly enhanced when the mtTFA-GX mutant was used (Fig. 4B). This indicates that the cysteine-dependent secondary structure of mtTFA may regulate its association with TRX2. These mutants, as well as wild-type mtTFA, could bind to damaged DNA. Oxidized DNA binding was significantly increased when the mtTFA-GX mutant was used (Fig. 4C). The enhancement of the DNA binding activity of mtTFA by TRX2 was observed for all mtTFA mutants (Fig. 4D).

\section{Discussion}

In this study, we identified a novel interaction of mtTFA with TRX2. Cytosolic thioredoxin has a wide variety of biological activities (28). Thioredoxin participates in the regulation of apoptosis via a direct interaction with ASK1 and protects cells against oxidative stress (29). In addition to cytosolic TRX1, cells contain another TRX, TRX2, which is localized in mitochondria. Expression of the TRX1 and TRX2 genes is upregulated in cisplatin-resistant cells (30). Nuclear HMG box proteins are often upregulated in cisplatin-resistant cells (1). Here, we observed a significant increase in the levels of the mitochondrial HMG box protein mtTFA in cisplatinresistant cells. Collectively, these data suggest a functional interaction between mtTFA and TRX2 because both proteins are localized in mitochondria. Mitochondria act as suppliers of ATP and produce ROS. On the other hand, mitochondria function as central players in modulating apoptosis. Little is known regarding the function of TRX2 and its potential role in apoptosis (31). It has been shown that overexpression of TRX2 makes cells resistant to etoposide (32). Our data also reveal that TRX2 expression is upregulated in cisplatinresistant cells, consistent with the fact that drug-resistant cells often show apoptosis-resistant phenotypes. Similar results have previously been reported, such as the finding that both TRX1 and TRX2 expression are increased in doxorubicinresistant ovarian cancer cells (33). Additionally, significantly increased levels of apoptosis have been observed in mtTFAknockout mice, suggesting that mtTFA also plays an important 
A

\begin{tabular}{|c|c|c|c|}
\hline \multirow[b]{2}{*}{ GST-mtTFA } & \multirow[b]{2}{*}{ GST } & 4050 & \multirow{2}{*}{22324} \\
\hline & & Box1 & \\
\hline & CC RV & WFSSVLASCPKKPV... & $\cdots \cdots$ KYGAEEC 246 \\
\hline & GC RV & WFSSVLASGPKKPV ... & $\cdots$ KYGAEEC * \\
\hline & $\mathrm{CX} \mathrm{RV}$ & WFSSVLASCPKKPV $\cdots$ & $\cdots$ KYGAEE * \\
\hline & GX RV & WFSSVLASGPKKPV $\cdots$ & $\cdots$ KYGAEE * \\
\hline
\end{tabular}

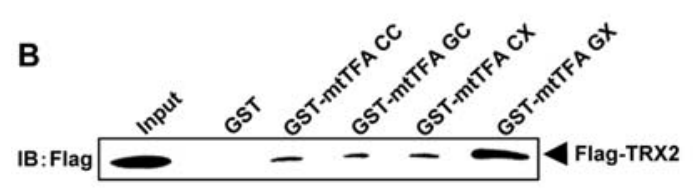

C

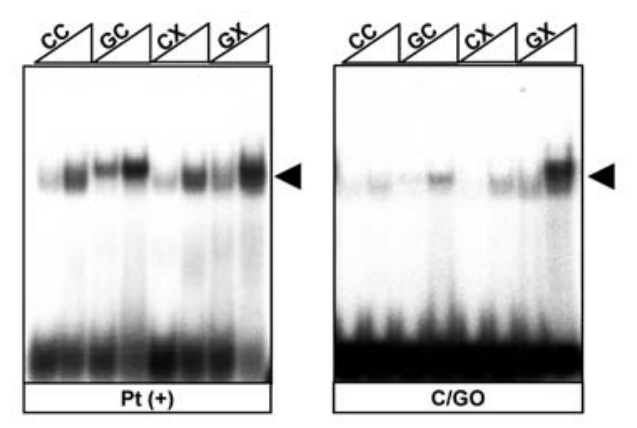

D

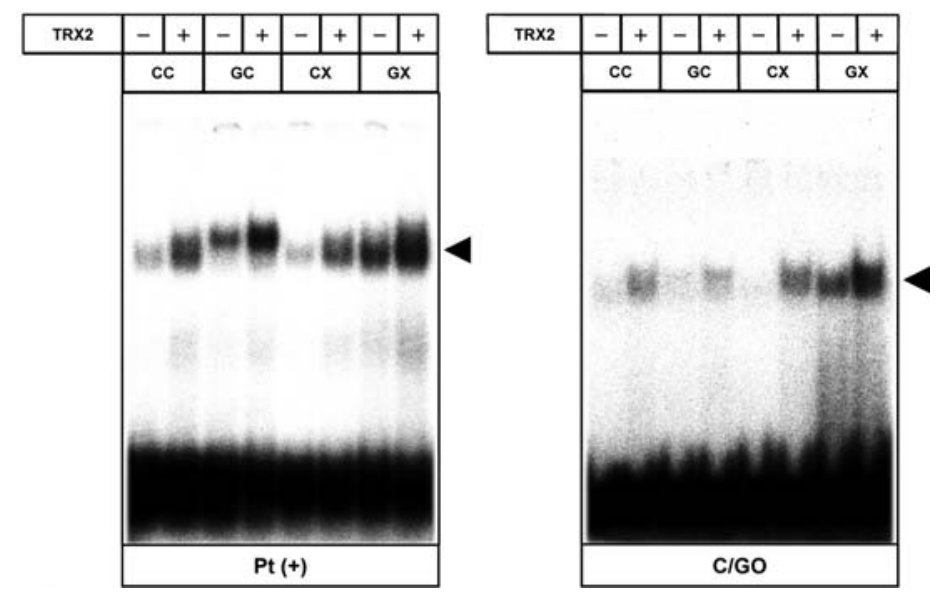

Figure 4. Effect of mtTFA mutation on binding to cisplatin-damaged or oxidized DNA. (A) Schematic representation of a GST-mtTFA fusion protein and its mutation of two cysteine residues (C49G and/or C246X). CC, GC, CX and GX indicate wild-type, C49G, C246X, C49G and C246X, respectively. (B) GST fusion proteins immobilized on glutathione-sepharose $4 \mathrm{~B}$ beads were incubated with Flag-TRX2 expressed in bacteria. Bound protein samples representing $10 \%$ of the input were subjected to SDS-PAGE and Western blot analysis with anti-Flag antibody. (C) Purified GST fusion proteins (30 and 90 ng) were incubated with ${ }^{32} \mathrm{P}$-labeled double-stranded oligonucleotides $(0.4 \mathrm{ng} / \mu \mathrm{l})$ containing cisplatin cross-linked or 8-oxo-dG (C/GO). Binding complexes were subjected to EMSAs. The arrowhead indicates DNA-protein complexes. (D) Purified GST fusion proteins (90 ng) were mixed with GST or GST-TRX2, and incubated with ${ }^{32} \mathrm{P}$-labeled double-stranded oligonucleotides $(0.4 \mathrm{ng} / \mu \mathrm{l})$ containing cisplatin cross-linked or 8 -oxo-dG (C/GO). Binding complexes were subjected to EMSAs. - and + indicate GST (90 ng) and GST-TRX2 (90 ng), respectively. The arrowhead indicates DNA-protein complexes.

role in apoptosis. mtTFA functions not only as a transcription factor, but also as DNA binding protein, like nuclear chromatin, to protect mtDNA from DNA damage. Fig. 2 shows that TRX2 supports the DNA binding activity of mtTFA to damaged DNA through a direct interaction.

We previously showed that both HMG box 1 and HMG box 2 motifs could interact independently with p53, which is localized to mitochondria under conditions of DNA damage stress (34). TRX2 interacts with the HMG box 1 motif of mtTFA (Fig. 2C). These findings indicate that mode of interaction of TRX2 with mtTFA is completely different from that of the interaction with p53 (22). Although there is some similarity in the primary amino acid sequences between HMG box 1 and HMG box 2, TRX2 only interacts with HMG box 1. This suggests that the secondary structure of mtTFA may modulate its association with TRX2. We then introduced mutations at two cysteine residues, positions 49 and 246 (Fig. 4A). The mutant mtTFA proteins could bind equally well to damaged DNA as wild-type mtTFA. However, the association of TRX2 with mtTFA was enhanced when the mtTFA-GX mutant was used. TRX2 can support DNA binding by mtTFA, even when a conformational change in mtTFA is 
induced by ROS, suggesting that mtTFA can still bind and protect mtDNA under conditions of oxidative stress.

The physiological multimerization of mtTFA may efficiently support DNA binding to mtDNA. A conformational change in mtTFA might inhibit multimerization. Therefore, TRX2 can enhance the DNA binding activity of damaged mtTFA, which cannot form multimers, to protect mtDNA. Characterization of the interaction of TRX2 with mtTFA will aid our understanding of the mtTFA function in both normal and pathological conditions.

\section{Acknowledgements}

Grant support: This study was supported by KAKENHI (17016075), a UOEH Grant for Advanced Research, and The Vehicle Racing Commemorative Fundation. We thank Satoko Takazaki, Seiko Mifune and Saori Tabata for their technical assistance.

\section{References}

1. Torigoe $\mathrm{T}$, Izumi $\mathrm{H}$, Ishiguchi $\mathrm{H}$, Yoshida $\mathrm{Y}$, Tanabe $\mathrm{M}$, Yoshida T, Igarashi T, Niina I, Wakasugi T, Imaizumi T, Momii Y, Kuwano M and Kohno K: Cisplatin resistance and transcription factors. Curr Med Chem 5: 15-27, 2005.

2. Loeb LA, James EA, Waltterscorph AM and Klebanoff SJ: Mutagenesis by the autoxidation of iron with isolated DNA. Proc Natl Acad Sci USA 85: 3918-3922, 1988.

3. McBride TJ, Preston BD and Loeb LA: Mutagenic spectrum resulting from DNA damage by oxygen radicals. Biochemistry 30: 207-213, 1991.

4. Weitzman SA and Gordon LI: Inflammation and Cancer: role of phagocyte-generated oxidants in carcinogenesis. Blood 76: $655-663,1990$

5. Cortopassi GA and Arnheim N: Detection of a specific mitochondrial DNA deletion in tissues of older humans. Nucleic Acids Res 18: 6927-6933, 1990.

6. Maccabee M, Evans JS, Glackin MP, Hatahet Z and Wallace SS Pyrimidine ring fragmentation products: effects of lesion structure and sequence context on mutagenesis. J Mol Biol 236: 514-530, 1994.

7. Soong NW, Hinton DR, Cortopassi G and Arnheim N: Mosaicism for a specific somatic mitochondrial DNA mutation in adult human brain. Nat Genet 2: 318-323, 1992.

8. Corral-Debrinski M, Horton T, Lott MT, Shoffner JM, Beal MF and Wallace DC: Mitochondrial DNA deletions in human brain: regional variability and increase with advanced age. Nat Genet 2: 324-329, 1992

9. Polyak K, Li Y, Zhu H, Lengauer C, Willson JK, Markowitz SD, Trush MA, Kinzler KW and Vogelstein B: Somatic mutations of the mitochondrial genome in human colorectal tumours. Nat Genet 20: 291-293, 1998.

10. Habano W, Nakamura S and Sugai T: Microsatellite instability in the mitochondrial DNA of colorectal carcinomas: Evidence for mismatch repair systems in mitochondrial genome. Oncogene 17: 1931-1937, 1998.

11. Wallace DC: Mitochondrial diseases in man and mouse. Science 283: 1482-1488, 1999.

12. Parisi MA and Clayton DA: Similarity of human mitochondrial transcription factor 1 to high mobility group proteins. Science 252: 965-969, 1991.

13. Larsson NG, Wang J, Wilhelmsson H, Oldfors A, Rustin P, Lewandoski M, Barsh GS and Clayton DA: Mitochondrial transcription factor A is necessary for mtDNA maintenance and embryogenesis in mice. Nat Genet 18: 231-236, 1998.

14. Takamatsu C, Umeda S, Ohsato T, Ohno T, Abe Y, Fukuoh A, Shinagawa H, Hamasaki N and Kang D: Regulation of mitochondrial D-loops by transcription factor A and single-stranded DNA-binding protein. EMBO Rep 3: 451-456, 2002.

15. Pil PM and Lippard SJ: Specific binding of chromosomal protein HMG1 to DNA damaged by the anticancer drug cisplatin. Science 256: 234-237, 1992.
16. Hughes EN, Engelsberg BN and Billings PC: Purification of nuclear proteins that bind to cisplatin-damaged DNA: identity with high mobility group proteins 1 and 2 . J Biol Chem 267: 13520-13527, 1992.

17. Billings PC, Davis RJ, Engelsberg BN, Skov KA and Hughes EN: Characterization of high mobility group protein binding to cisplatin-damaged DNA. Biochem Biophys Res Commun 188: 1286-1294, 1992.

18. Turchi JJ, Li M and Henkels KM: Cisplatin-DNA binding specificity of calf high-mobility group 1 protein. Biochemistry 35: 2992-3000, 1996.

19. Yoshida Y, Izumi H, Ise T, Uramoto H, Torigoe T, Ishiguchi $H$, Murakami T, Tanabe M, Nakayama Y, Itoh $\mathrm{H}$, Kasai $\mathrm{H}$ and Kohno K: Human mitochondrial transcription factor A binds preferentially to oxidatively damaged DNA. Biochem Biophys Res Commun 295: 945-951, 2002.

20. Murakami T, Shibuya I, Ise T, Chen ZS, Akiyama S, Nakagawa M, Izumi H, Nakamura T, Matsuo K, Yamada Y and Kohno K: Elevated expression of vacuolar proton pump genes and cellular $\mathrm{pH}$ in cisplatin resistance. Int J Cancer 93: 869-874, 2001

21. Fujii R, Mutoh M, Niwa K, Yamada K, Aikou T, Nakagawa M, Muwano M and Akiyama S: Active efflux system for cisplatin in cisplatin-resistant human KB cells. Jpn J Cancer Res 85: 426-433, 1994.

22. Yoshida $Y$, Izumi $H$, Torigoe $T$, Ishiguchi $H$, Itoh $H$, Kang D and Kohno K: p53 physically interacts with mitochondrial transcription factor A and differentially regulates binding to damaged DNA. Cancer Res 63: 3729-3734, 2003.

23. Uramoto H, Izumi H, Ise T, Tada M, Uchiumi T, Kuwano M, Yamamoto K, Funa K and Kohno K: p73 interacts with c-Myc to regulate Y-box-binding protein-1 expression. J Biol Chem 277: 31694-31702, 2002.

24. Izumi H, Ohta R, Nagatani G, Ise T, Nakayama Y, Nomoto M and Kohno K: p300/CBP-associated factor (P/CAF) interacts with nuclear respiratory factor-1 to regulate the UDP-N-acetyl$\alpha$-D-galactosamine: polypeptide $\mathrm{N}$-acetylgalactosaminyltransferase-3 gene. Biochem J 373: 713-722, 2003.

25. Shiota M, Izumi H, Onitsuka T, Miyamoto N, Kashiwagi E, Kidani A, Hirano G, Takahashi M, Naito S and Kohno K: Twist and $\mathrm{p} 53$ reciprocally regulate target genes via direct interaction. Oncogene 27: 5543-5553, 2008.

26. Wakasugi T, Izumi H, Uchiumi T, Suzuki H, Arao T, Nishio K and Kohno K: ZNF143 interacts with p73 and is involved in cisplatin resistance through the transcriptional regulation of DNA repair genes. Oncogene 26: 5194-5203, 2007.

27. Antoshechkin I, Bogenhagen DF and Mastrangelo IA: The HMG-box mitochondrial transcription factor xl-mtTFA binds DNA as a tetramer to activate bidirectional transcription. EMBO J 16: 3198-3206, 1997.

28. Powis G, Mustacich D and Coon A: The role of the redox protein thioredoxin in cell growth and cancer. Free Radic Biol Med 29: 312-322, 2000.

29. Saitoh M, Nishitoh H, Fujii M, Takeda K, Tobiume K, Sawada Y, Kawabata M, Miyazono K and Ichijo H: Mammalian thioredoxin is a direct inhibitor of apoptosis signal-regulating kinase (ASK) 1. EMBO J 17: 2596-2606, 1998.

30. Yokomizo A, Ono M, Nanri H, Makino Y, Ohga T, Wada M, Okamoto T, Yodoi J, Kuwano M and Kohno K: Cellular levels of thioredoxin associated with drug sensitivity to cisplatin, mitomycin C, doxorubicin, and etoposide. Cancer Res 55: 4293-4296, 1995.

31. Patenaude A, Murthy MRV and Mirault ME: Mitochondrial thioredoxin system; effects of TrxR2 overexpression on redox balance, cell growth, and apoptosis. J Biol Chem 279: 27302-37314, 2004.

32. Damdimopoulos AE, Vizuete AM, Huikko MP, Gustafsson JA and Spyrou G: Human mitochondrial thioredoxin; involvement in mitochondrial membrane potential and cell death. J Biol Chem 277: 33249-33257, 2002.

33. Kalinina EV, Chernov NN, Saprin AN, Kotova YN, Gavrilova YA, Chermnykh NS and Shcherbak NP: Expression of genes for thioredoxin1 and thioredoxin2 in multidrug resistance ovarian carcinoma cells SKVLB. Bull Exp Biol Med 144: 301-303, 2007.

34. Imamura $\mathrm{T}$, Izumi $\mathrm{H}$, Nagatani G, Ise $\mathrm{T}$, Nomoto $\mathrm{M}$, Iwamoto $\mathrm{Y}$ and Kohno K: Interaction with p53 enhances binding of cisplatin-modified DNA by high mobility group 1 protein. J Biol Chem 276: 7534-7540, 2001 